\title{
Development of a tool to optimize economic and environmental feasibility of food waste chains
}

\author{
Irene Celli ${ }^{1}$. Edoardo Brunori ${ }^{1}$ - Michele Eugeni ${ }^{1}$. Cecilia Andrea Cristinariu ${ }^{1}$ Mauro Zampilli ${ }^{1}$ Sara Massoli ${ }^{1}$. \\ Pietro Bartocci ${ }^{1,2}$. Valentina Caldarelli ${ }^{1} \cdot$ Stefano Saetta ${ }^{1} \cdot$ Gianni Bidini $^{1} \cdot$ Francesco Fantozzi $^{1}$
}

Received: 12 September 2021 / Revised: 15 November 2021 / Accepted: 22 November 2021 / Published online: 7 January 2022

(c) The Author(s) 2022

\begin{abstract}
The Sustainable Development Goal 12.3 focuses on food and its inedible parts that exit the supply chain and thus are lost or wasted. This work addresses the food waste problem by presenting the development of a tool to design business models to reduce the production of food waste. This has been developed within the LIFE16 project iRexfo, coordinated by the University of Perugia. The tool aims at transferring the results obtained in a pilot region (Umbria, Italy) to 4 other regions in Europe. It has been coded in Python and has a graphical user interface (GUI) to insert inputs and display outputs. The GUI has been developed in FLASK and it is hosted in the website of PythonAnywhere. A case study on the application of the software is also presented, mainly based on data retrieved in the Umbria region, Italy. Together with economic analysis, also, environmental assessment is performed.
\end{abstract}

Keywords Tool $\cdot$ Feasibility $\cdot$ LCA $\cdot$ Python $\cdot$ Logistics $\cdot$ FLASK

$\begin{array}{ll}\text { Nomenclature } \\ \text { bool } & \text { Boolean }(-) \\ \text { d } & \text { Distance }(\mathrm{km}) \\ \text { FC } & \text { Fuel consumption }(\mathrm{L}) \\ \text { FP } & \text { Fuel price }(€ / \mathrm{L}) \\ \text { int } & \text { Integer }(-) \\ \text { MPC } & \text { Man power consumption }(\mathrm{h}) \\ \text { N } & \text { Number of suppliers }(-) \\ \text { q } & \text { Quantity of food waste per supplier }(\mathrm{t}) \\ \text { Q } & \text { Total annual quantity of food waste }(\mathrm{t}) \\ \text { str } & \text { String }(-) \\ \text { TC } & \text { Transport cost }(€) \\ \text { v } & \text { Maximum quantities available for each supplier }(\mathrm{t}) \\ \text { i } & \text { i-th Supermarket }\end{array}$

Pietro Bartocci

pbartocci@icb.csic.es

1 Department of Industrial Engineering, University of Perugia, Via G. Duranti 67, 06125 Perugia, Italy

2 Instituto de Carboquímica (ICB-CSIC), Miguel Luesma Castán 4, 50018 Zaragoza, Spain

\section{Introduction}

The SDG 12.3 focuses on food that exits the supply chain and thus is lost or wasted [1,2]. It covers three sectors: food retail; households; and food service.

The loss of edible food involves all the production chain, so we can also define "food loss" as the waste generated during the production and transport of food. On the other hand, food waste is defined as the food discarded during the retail and consumption phase. Both food loss and food waste have been measured with specific indexes by UNEP [3] and FAO [4], respectively.

Since we cannot avoid losses during the various phases which take place during the production, we should not at least waste food at the end of the supply chain (i.e. distribution and consumption). In fact, there are many ways in which food is wasted by consumers and retailers:

-fresh products that deviate from what is considered optimal, in terms of shape, size, and color, are often removed from the supply chain during sorting operations;

-food that is close to, at or beyond the "best-before" date is often discarded by retailers and consumers;

- large quantities of edible food are often unused or discarded from household kitchens and catering facilities [5]. 
Every year, the EU estimates that around 88 million tons of food waste are generated with associated costs evaluated at 143 billion euros, according to the European Commission [6]. To produce this waste, a volume of water equal to $250 \mathrm{~km}^{3}$ was consumed, together with $30 \%$ of the world's agricultural land [7]; therefore, food waste not only is an economic issue but also consumes the limited resources available in the environment. This makes clearly visible consequences of economic growth on the food-energywater NEXUS. Reducing food waste could support the fight against climate change, considering that it alone generates about $8 \%$ of global greenhouse gas emissions [7].

Many research works have been financed to quantify the actual food loss and waste, taking also into account the ethical implications of that unnecessary waste [8-15]. In order to define a future reduction strategy, the recent UNEP (United Nations Environment Programme) report of 2021 on food waste has developed a food waste index [3]. In order to respect the goals set by the UN during the years, the UE financed many projects, to implement food waste management into a circular economy model, aiming at the final reduction of food waste and the conversion of inedible food waste into energy. One of these is, for example, the i-Rexfo LIFE16 project, coordinated by the University of Perugia, see [16-21]. This project aims at reducing expired food production and its disposal in landfills, by designing two types of interventions:

-Expired Food Reduction (REF) chains;

-Expired Food Energy (EFE) chains.

In the first type of intervention, the food waste is prevented with communication and donation actions, while in the second part, the disposal in landfill of inedible food waste is avoided using it for the generation of biogas. The business model proposed by the project wants to show that both the chains (EFE and REF) can be economically feasible, if we use part of the income generated by the EFE chains to finance part of the costs of the REF chains. The model is tested firstly in the Umbria region and then will be applied to other two regions in Italy and two regions in Hungary. To transfer the business model developed in the Umbria region to other territories situated in Europe and outside Europe, it is needed to develop a transferability tool, capable of calculating the economic and environmental feasibility of the different food waste reduction chains and food waste reuse chains. During the i-REXFO project, a specific tool has been developed, which has innovative features and it is tailored to the case study developed in the Umbria Region. Before presenting the methodology and the results of the work, a short overview of other tools, which are already available in the literature to trace and reduce food waste production, is presented.

\subsection{Other existing tools used to address the food waste problem}

Many tools are available in the literature for food waste reduction. The University of Leeds and KEDGE Business School have done an interesting study on the possible use of social media to promote the cause of food waste reduction [22]. AZTI has realized interesting studies in Spain developing decision-making tools based on GIS to manage food waste reduction [23]. Even packaging can be adapted to work as a tool to reduce food waste production, as reported in a study of the Polytechnic University of Valencia [24]. In a collaborative work of Uppsala Swedish University of Agricultural Science, Ostfold Research and Natural Resources Institute Finland, it was demonstrated that using smart scales and specific software, a significant reduction in food waste can be obtained in the hospitality sector [25].

The CE evaluator [26] helps to estimate the circularity of investment dossiers, thereby increasing the effectiveness of investments in the circular transition. It has a visual representation of the results, providing an insight into the extent to which the project files address the various dimensions of circularity and enabling files to be compared with one another. The tool takes account of circularity in the sense of product and material flows. CEvaluator also includes an evaluation of ecological sustainability. The checklist reports typical funding opportunities and risks related to circular cases and revenue models.

The GISWASTE [27] Life project has developed an IT tool, which assists users in choosing the best options to recover and reuse agri-food waste through the production of biogas and animal feed. In addition to the environmental benefits, there are also economic benefits, associated with the creation of a new sub-sector, which will give rise to the development of new firms, specialized in waste management and recovery.

Toogoodtogo is an app, which aims at reducing waste, from the first steps of production to the distribution to consumers, involving also the HORECA sector [28]. It provides a more consumer-centered application, since it gives the chance to have access to the surplus expiring food from local stores. It also puts together shops and food producers into a circular economy model, giving them a tool for reducing waste.

The FEEDUP application [29] is a centralized online marketplace, based on blockchain technology and brings all different parties together in one virtual space, while contributing to a more circular production. It enables trade at a faster pace, to reduce food losses and food waste in a fully traceable system. It also addresses Sustainable Development Goals (SDG) 2, 8, and 12, in collaboration with 
governments, the private sector, NGO's, certification bodies, logistics operators, and suppliers in a single platform. Since it is based on a wide network, it allows to quantify, track, monitor, and report the food waste impact annually every year at all levels (including small-scale farmers).

\subsection{Objective of the work}

The objective of this work is the development of a userfriendly software application named transferability tool capable of evaluating both economic and environmental convenience of two types of chains: EFE chains, which mean Expired Food Energy chains; REF chains, which mean Reduction of Expired Food chains. The transferability tool is designed to be tested in the first two years of the i-REXFO LIFE16 project in a pilot region (Umbria, Italy) and eventually used to transfer the approach to other European regions in the third year of the project. Moreover, private commercial beneficiaries will be engaged as support to non-commercial beneficiaries. The tool will be used to evaluate the feasibility of the REF and EFE chains and to help stakeholders across the EU, who intend to implement these chains. It will provide first indications of the options available to reduce food waste when implementing i-REXFO model and its economic, environmental, and social impacts. The tool is a calculator system developed by UNIPG, characterized by two sections to evaluate the impacts of the chain implementation, starting by the food characterization, food availability, localization, and typology (both expiring and expired). For both chains, the tool will allow the optimization of the supply chain, to minimize economic and environmental costs on a life cycle approach. The tool will help to implement the i-REXFO approach, by supporting key actors of both the EFE and the REF chains. The tool will contain a database of expired food properties that will be classified in food categories, according to the FAO classification which has been already used in the EU project FUSION (Reducing Food Waste Through Social Innovation). The database will be developed through literature data or laboratory tests for the evaluation of Biochemical Methane Potential. This information will be essential to determine sludge dilution or concentration at the real plant. The analysis will be performed at the laboratories of the Biomass Research Center of the University of Perugia. The database will provide methane yields from different food mixtures that are the base for the techno-economic and environmental design of EFE chains. The income produced from bioenergy sales performed in the framework of the REF chains will support part of the costs which will be undergone in the REF chains. The tool also calculates the investment cost, the transport cost (expressed in $€ / t$ ), the cost opportunity of the avoided saved disposal (expressed in $€ / t$ ), energy production, environmental benefits and revenues, to allow the closing of the business plan.

\section{Materials and methods}

The aim of the i-REXFO project is the realization of an open-source tool for the optimization of the proposed circular economy model. It allows the user to have a clear view of all the possible scenarios and to make decisions based on economic and environmental issues.

For this sake, an optimization script in Python has been developed and inserted in a user-friendly graphical user interface (GUI) developed in FLASK and uploaded on python anywhere website, algorithms to import data from Excel and evaluate the resulting outputs throughout the optimization routine. The final tool is available in this website: https://irexfo2.pythonanywhere.com/.

\subsection{Mathematical optimization logic}

The first step is to write the mathematical relations of our model, starting from the objective function which should be minimized:

$f(q)=\sum_{i=1}^{N} q_{i} \cdot d_{i}$

where $\mathrm{N}$ is the total number of supermarkets, qi is the weekly quantity of expired food picked from every supermarket, and di is the distance between the biogas production plant and the i-th supermarket.

Obviously, the amount of food collected for every customer cannot be higher than the quantity of expired food available each week, so we have to impose one constraint per supermarket, based on the maximum quantity available:

$q_{i} \leq v_{i}$ with $1 \leq i \leq N$

where vi are maximum quantities available for each supermarket. Finally, we have to impose an equality constraint, because the total amount of food collected every week (expressed in tons) must be equal to the annual target quantity $(\mathrm{Q})$ divided by the number of weeks in a year, which is 52 :

$\sum_{i=1}^{N} q_{i}=\frac{Q}{52}$

Now that the main equations of the model relations have been explained, starting from the input data entered by the user (vi and di), we should run the optimization tool to obtain the optimal quantities qi for each customer.

\subsection{The tool code}

Once we have defined the mathematical model for our problem, we start writing the code for the tool in Python 


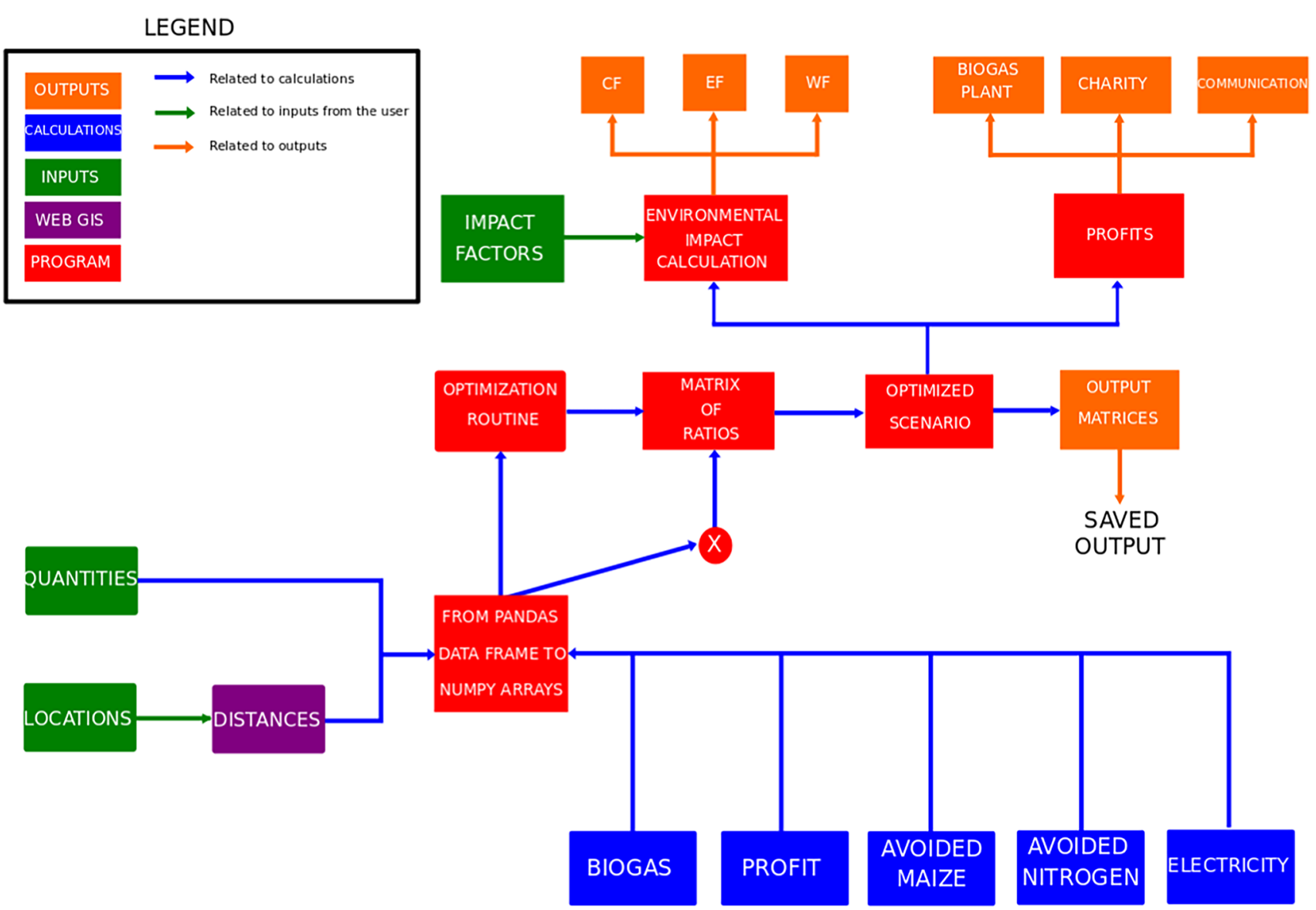

Fig. 1 Visual scheme of the Python tool, where CF stands for carbon footprint, EF stands for environmental footprint, WF stands for water footprint

language. The scheme of the logic of the tool is shown in Fig. 1.

As it can be seen from Fig. 1, each step of the tool is indicated with a different colour, where:

-Orange indicates the outputs;

-Blue indicates the imported inputs, which can be imported also from excel files (in the case of data which are already in possess of the user of the tool);

-Green indicates the input inserted by the user directly in the graphical user interface;

-Light blue indicates the values which are calculated, like the data used for example for the estimate of the environmental impact, which is calculated based on tables of constants (see next paragraph)

-Red which are the commands or that allow to switch from one program phase to another.

The different types of food waste considered in this study were obtained from local supermarkets. The chemical-physical properties were measured at the Analysis Lab of the Biomass Research Centre described in previous works
[30-34]. A TGA 701 LECO has been used to perform proximate analysis and determine moisture, ash, total solid and volatile solid content, according to the following norms: UNI EN ISO 18134-2:2015, UNI EN ISO 18122:2016, and UNI EN 15,148:2010. The elemental analyzer Truspec CHN LECO was used to perform ultimate analysis, to determine the contents of carbon, hydrogen, and nitrogen, according to UNI EN ISO 16948:2015. The characterization of the material was a preliminary step to analyze its biomethane potential; in fact, based on its proximate and ultimate analysis, a mixture of inoculum and raw material was performed, maintaining always a fixed concentration of volatile solids. The biomethane potential (BMP) assay can be used as an index of the anaerobic biodegradation potential, as it is the experimental value of the maximum quantity of methane produced per gram of volatile solids. This is analyzed with the BMP test, which consists in measuring the biomethane or biogas produced by a known quantity of substrates in batch conditions. The BMP tests were carried out in a multibatch reactor system $[20,35,36]$.

After the input data have been uploaded into the tool by the user and the totals and the economic and environmental 
indicators have been calculated, the tool optimizes the collection of the weekly values of waste food produced by supermarkets and HORECA. The optimization routine is the most complex part of the tool and it is explained in the next paragraph. More detail on the input phase is proposed in the supplementary material.

\subsection{Optimization routine}

At first, we have initialized an empty list, in which we could write the resulting optimized quantities. Dealing with the implementation of the mathematical model, we have first stated the constraints about the weekly target quantity using the "LinearConstraint" package of Python. As we can see from the relations in the supplementary material, the sum of all qi, whose values are our unknown variables, has to be equal to $2500 / 52$, which represents the target (2500 t/year) allocated to each week.

After the definition of the constraints, it is needed to impose the limits for our unknown variables; in particular, these quantities must fall between 0 and the maximum weekly quantity available at each supermarket vi. The value 0 is set because we cannot have negative quantities, while each value vi is a component of the array $\mathrm{v}$, defined above:

The variable limits are defined as a list, whose elements represent limits that every corresponding unknown variable must not exceed, and the index $\mathrm{k}$ is used to fill the upper side of boundaries with values contained in the array v. Now, the last step to implement the optimization model is to build the objective function which has to be finally minimized. As we have explained in the mathematical model section, this function is the product between the array of unknown variables $\mathrm{x}$, containing values qi, and the array $\mathrm{d}$ of distances, so we have created the "objective_function" that represents the objective to minimize with the command "Scipy.optimization.minimize."

Now, we can use the command "minimize" to perform our optimization; inputs of this command are the objective function, an $\mathrm{N}$-long array of zeros to define initial values, all the arguments that we want to pass to the function (in this case the array of distances d), and all the constraints and limits. The final results are written in an object, named "res."

The optimization result "res" is represented as an "OptimizeResult" object, whose attributes are:

-x (n-d-array): the solution of the optimization.

-Success (bool): whether or not the optimizer exited successfully.

-Status (int): termination status of the optimizer.

-Message (str): description of the cause of the termination or a successful message.

-fun, jac (n-d-array): values of the objective function and its Jacobian. -nfev, njev (int): number of evaluations of the objective functions and of its Jacobian.

-Nit (int): number of iterations performed by the optimizer.

We could read the whole object "res," but we are interested only in knowing the array of solutions $x$, so we have defined an array "q" as the array "res.x" rounded to 2 decimal points. In order to avoid that the algorithm replaces the previous values, we used the ".append" command to add the new values to the list "Q."

Now, we proceed with the last part of the script, whose task is to show to the user the results about the optimization process.

Once the Q list has been completed, we transformed it into an array, which was a most suitable format, and then calculated the transposed through the ".transpose()" command.

The results of the optimization routine are saved in matrices as well, which are a subset of the original matrices inserted by the user on food waste availabilities and have been optimized. The realization of the abovementioned matrices is described with more detail in the supplementary materials. Finally, all the data are saved in the different sheets of an excel file.

\subsection{Profit evaluation}

To evaluate the profit coming from biogas production and its transformation into electricity, there is the need to perform an economic analysis, in which CAPEX (Capital Expenses) and OPEX (Operating Expenses) of the biogas plant must be taken into account, in addition to the expenses related to the transportation (Table 1). The inputs used in the economic

Table 1 Capital Expense (CAPEX) and Operating Expense (OPEX) of the biogas plant, data are elaborated from [34]

\begin{tabular}{lll}
\hline Component & Value & Unit of measure \\
\hline CHP plant & 600 & $€ / \mathrm{MWel}$ \\
Biogas plant & 600 & $€ /$ plant \\
$\begin{array}{l}\text { Building and logistics plus } \\
\quad \text { installations }\end{array}$ & 2.6 & $\mathrm{M} € /$ plant \\
Incubators & 40,000 & $€ /$ plant \\
Maintenance & 0.30 & $€ / \mathrm{kWh}$ \\
Labor & 45,000 & $€ /$ person \\
Biomass & 11 & $€ / \mathrm{t}$ \\
Discount rate & 5 & $\%$ \\
Taxes & 24 & $\%$ \\
Debt interest & 2 & $\%$ \\
Debt ratio & 50 & $\%$ \\
Project life & 20 & years \\
Electricity export rate & 140 & $€ / \mathrm{MWh}$ \\
\hline
\end{tabular}


feasibility analysis are the ones shown below. The methodology has been mainly taken from [19, 34].

In addition to that, there is also the need to evaluate the methane yield of the biomass quantities in order to calculate the profit. This is done based on the data reported in Fig. 3.

\subsection{Environmental evaluation}

To evaluate the environmental effect associated with i-REXFO business model implementation, an LCA (Life Cycle Assessment) is performed by the tool, to assess the environmental impact associated with all the stages of the life-cycle of a commercial product, process, or service. In our study, we referred to the standards ISO 14040 e ISO 14044 to implement the LCA. According to these standards, our life cycle analysis was divided in four main steps:

-definition of the aim of the analysis and the field of application;

-inventory analysis;

-impacts evaluations during the life cycle;

-interpretation of the life cycle.

Starting from these bases, there are different methods to realize an LCA.

In this case, the methodology was based a consequential LCA (cLCA) approach. In fact, the study wants to provide information about the consequences of changes in the output of a product, also including the effects not regarding the product life cycle.

For i-REXFO, the final indicators related to the environmental performance evaluation, which are shown in the Python program, are:

\section{-Carbon footprint ( $\mathrm{kgCO} /$ week) \\ -Environmental footprint (/week) \\ -Water footprint (/week) \\ -Energy demand (MJ/week)}

Table 2 Coefficients used for the carbon footprint calculation (source: Ecoinvent 3.5)

\begin{tabular}{lll}
\hline Impact analysis & Carbon footprint C.F & Unit of measure \\
\hline Avoided nitrogen & 0.05 & $\mathrm{~kg} / \mathrm{kg}$ \\
Digester & 0.00496 & $\mathrm{kgCO}_{2} \mathrm{eq} / \mathrm{kg} \mathrm{FW}$ \\
$\mathrm{CHP}$ & $3.86 \mathrm{E}-03$ & $\mathrm{kgCO}_{2} \mathrm{eq} / \mathrm{kg} \mathrm{FW}$ \\
Electricity transmission & $1.28 \mathrm{E}-03$ & $\mathrm{kgCO}_{2} \mathrm{eq} / \mathrm{kg} \mathrm{FW}$ \\
Digestate disposal in soil & $9.33 \mathrm{E}+00$ & $\mathrm{kgCO}_{2} \mathrm{eq} / \mathrm{kg} \mathrm{FW}$ \\
Urea & 3.15 & $\mathrm{kgCO}_{2} \mathrm{eq} / \mathrm{kg}$ urea \\
Electricity & 0.65 & $\mathrm{kgCO}_{2} \mathrm{eq} / \mathrm{kWh}$ \\
Maize & 0.137 & $\mathrm{kgCO}_{2} \mathrm{eq} / \mathrm{kg}$ maize \\
Transport & 0.1624 & $\mathrm{kgCO}_{2} \mathrm{eq} / \mathrm{t} * \mathrm{~km}$ \\
\hline
\end{tabular}

They are calculated using the constants shown in Table 2.

The coefficients used to calculate the environmental and water footprint are proposed in Tables 3 and 4, respectively.

The detail of the calculations on the environmental impact is proposed in the supplementary material and is in correspondence to what reported also in literature, see [19]

\section{Results}

In order to develop and test the Python software, the Umbria region was taken as a pilot and the model was tested with 22 providers of food waste (4 supermarkets and 18 food industries) and one treatment plant, mainly based on biogas technology. It is worthy to be noted that in practice, the suppliers of food waste are located also outside the region, but what characterizes the test is the fact that the treatment plans, which can be identified with the biogas plant is located in the region. The inputs for the model have been provided by a treatment plant, which is specialized on food waste treatment and is located in the same Umbria region (Italy).

Table 3 Coefficients used for the ecological footprint calculation (source: Ecoinvent 3.5)

\begin{tabular}{lll}
\hline Impact analysis & Water footprint C.F & Unit of measure \\
\hline Avoided nitrogen & 0.05 & $\mathrm{~kg} / \mathrm{kg}$ \\
Digester & $2.14067 \mathrm{E}-05$ & $\mathrm{~m}^{3} / \mathrm{kg} \mathrm{FW}$ \\
CHP & $6.22222 \mathrm{E}-09$ & $\mathrm{~m}^{3} / \mathrm{kg} \mathrm{FW}$ \\
Electricity transmission & $2.72356 \mathrm{E}-06$ & $\mathrm{~m}^{3} / \mathrm{kg} \mathrm{FW}$ \\
Digestate disposal in soil & 0.000000028 & $\mathrm{~m}^{3} / \mathrm{kg} \mathrm{FW}$ \\
Urea & 0.36 & $\mathrm{~m}^{3} / \mathrm{kg} \mathrm{urea}$ \\
Electricity & 2.8 & $\mathrm{~m}^{3} / \mathrm{kWh}$ \\
Maize & 0.00769 & $\mathrm{~m}^{3} / \mathrm{kg} \mathrm{maize}$ \\
Transport & 0.0079 & $\mathrm{~m}^{3} / \mathrm{t}^{*} \mathrm{~km}$ \\
\hline
\end{tabular}

Table 4 Coefficients used for the water footprint calculation (source: Ecoinvent 3.5)

\begin{tabular}{lcl}
\hline Impact analysis & Energy demand C.F & Unit of measure \\
\hline Avoided nitrogen & 0.05 & $\mathrm{~kg} / \mathrm{kg}$ \\
Digester & $1.39333 \mathrm{E}-07$ & $\mathrm{MJ} / \mathrm{kg} \mathrm{FW}$ \\
$\mathrm{CHP}$ & $2.42733 \mathrm{E}-07$ & $\mathrm{MJ} / \mathrm{kg} \mathrm{FW}$ \\
Electricity transmission & 0.000067408 & $\mathrm{MJ} / \mathrm{kg} \mathrm{FW}$ \\
Digestate disposal in soil & $8.57 \mathrm{E}-08$ & $\mathrm{MJ} / \mathrm{kg} \mathrm{FW}$ \\
Urea & 42.9 & $\mathrm{MJ} / \mathrm{kg} \mathrm{urea}$ \\
Electricity & 5.61 & $\mathrm{MJ} / \mathrm{kWh}$ \\
Maize & 0.759 & $\mathrm{MJ} / \mathrm{kg}$ maize \\
Transport & 1.98 & $\mathrm{MJ} / \mathrm{t}^{*} \mathrm{~km}$ \\
\hline
\end{tabular}




\subsection{Available quantities}

In the "Quantity" matrix, for each of the 22 suppliers, the weekly available food waste measured in tons is reported. Suppliers can be: supermarkets, HORECA, but also food industries. Obviously, the quantity provided by the HORECA is lower respect to that provided by the supermarket which is generally lower compared to that provided by the food industries. The final results of the data inserted on the availabilities are shown in Fig. 2. We can see a histogram, in which suppliers are on the $\mathrm{x}$-axis whereas the total corresponding annual available quantities are shown on the y-axis.

\subsection{Methane yields}

The transferability tool contains a database in which expired food properties are gathered and where food is classified in 16 different categories, according to the FAO classification (Table 5).

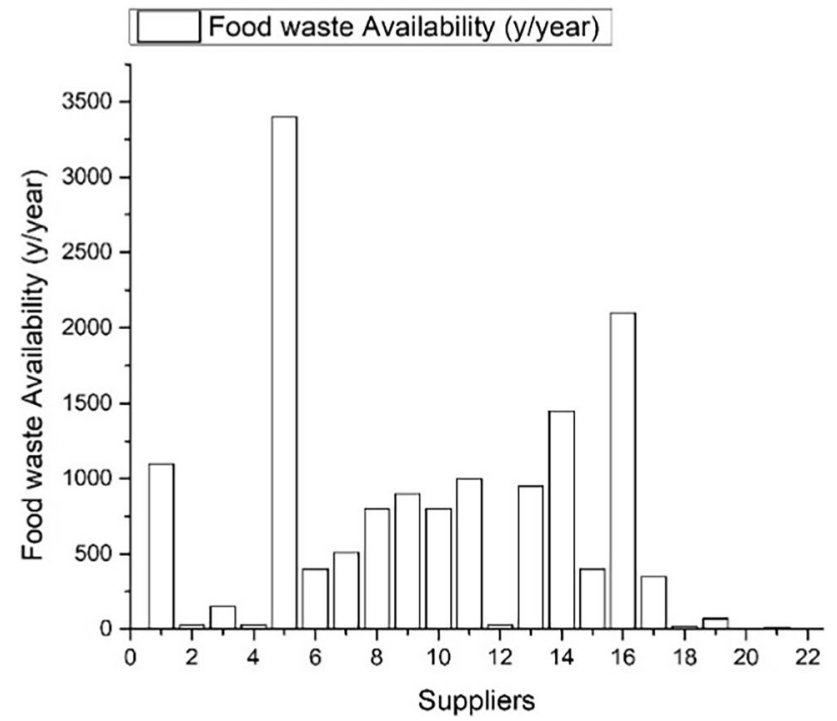

Fig. 2 Food waste availability in the case study, related to Umbria region (Italy)
Data were both obtained from literature and BMP (Biochemical Methane Potential) tests (see Fig. 3, taken from [19]). Those represent an essential way to determine sludge dilution, biogas production, and the energy which can be potentially produced by using food waste in biogas plants. To measure the biogas yield and composition, batch bottles have been used. These are containers equipped with pressure, temperature probes, and $\mathrm{pH}$ meter, in order to analyze the composition of biogas samples [34].

Usually, a higher methane yield is achieved with substrates containing a high amount of sugars, such as bread and onion or fats, like vegetable oils.

The results showing the final amount of methane obtained from the total availability of the food waste quantities are shown in Fig. 4.

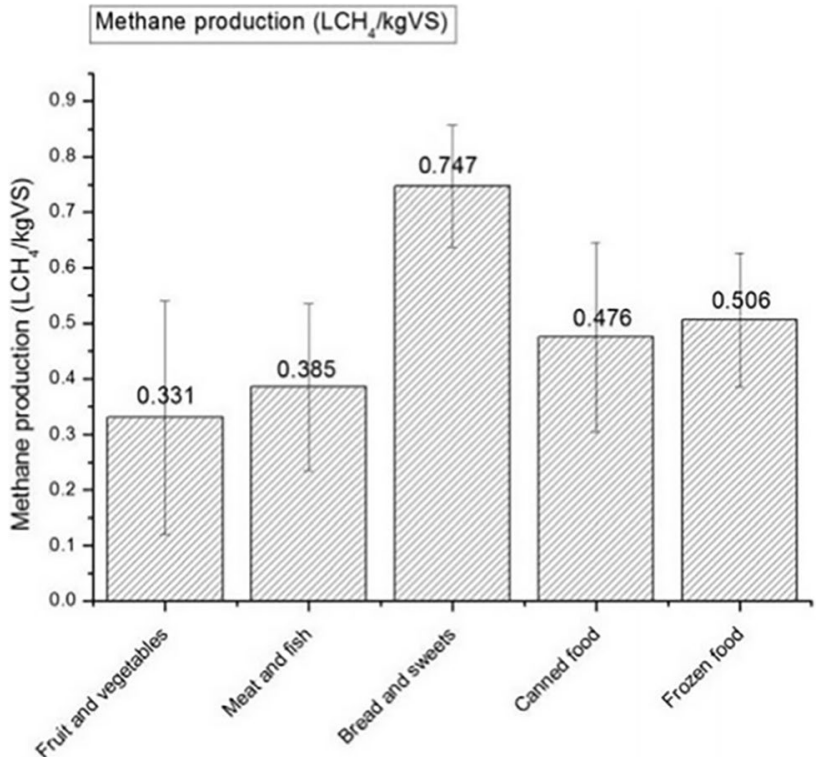

Fig. 3 Methane yields obtained by the anaerobic digestion of food waste categories (adapted from [19])

Table 5 Food categories

\begin{tabular}{llll}
\hline Categories & Food classification & Categories & Food classification \\
\hline 1 & Dairy products & 9 & Fish and fish products \\
2 & Fats, oil and grease (FOG) & 10 & Eggs and egg products \\
3 & Ice creams & 11 & Sweeteners, and sweet goods \\
4 & Fruit and vegetable & 12 & Salt, sauce, spice, soups \\
5 & Confectionary (canned goods) & 13 & Food stuff \\
6 & Cereals and cereals products & 14 & Beverages \\
7 & Bakery wares & 15 & Ready to eat food or restaurant waste \\
8 & Meat and Meat products & 16 & Others \\
\hline
\end{tabular}




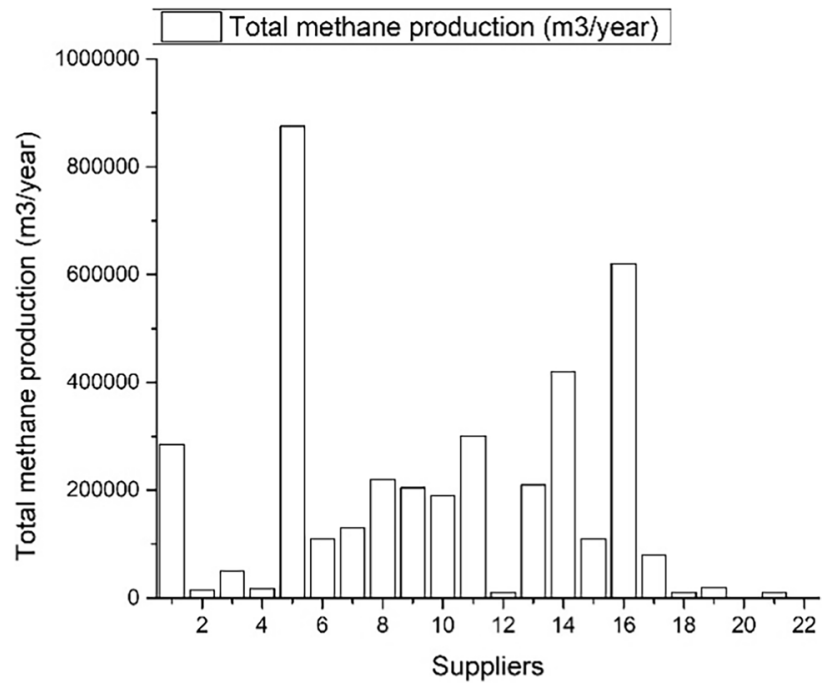

Fig. 4 Total methane production from the anaerobic digestion of food waste availabilities in the Umbria pilot case $\left(\mathrm{m}^{3} /\right.$ year)

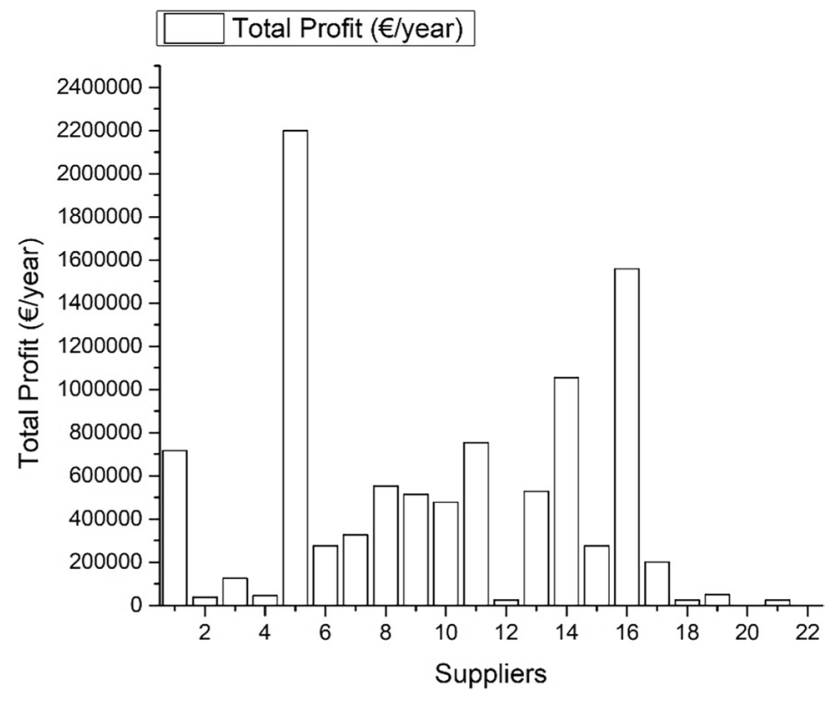

Fig. 5 Annual profit for the different quantities of food waste provided by each supplier in the Umbria region pilot case study

\subsection{Profit calculation}

The bar chart below (Fig. 5) represents the annual income, obtained on a weekly basis, by selling to the grid the electricity produced using the food waste availabilities provided by each supplier.

\subsection{Calculation of electricity production}

The results on "electricity" production show the amount of electrical energy ( $\mathrm{kWh}$ ) obtained by using the produced biogas. This can be seen in Fig. 6.

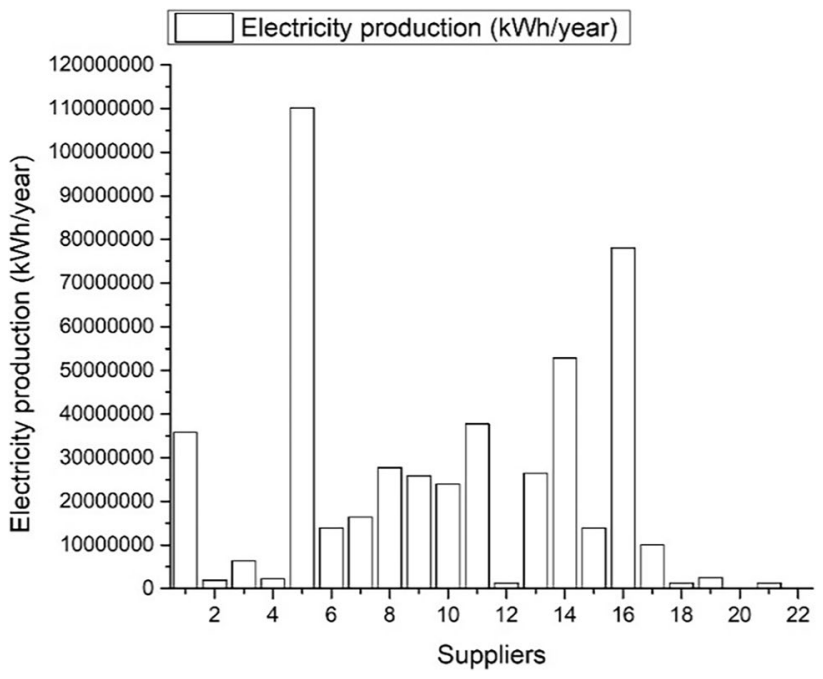

Fig. 6 Annual electricity produced from the food waste provided by each supplier

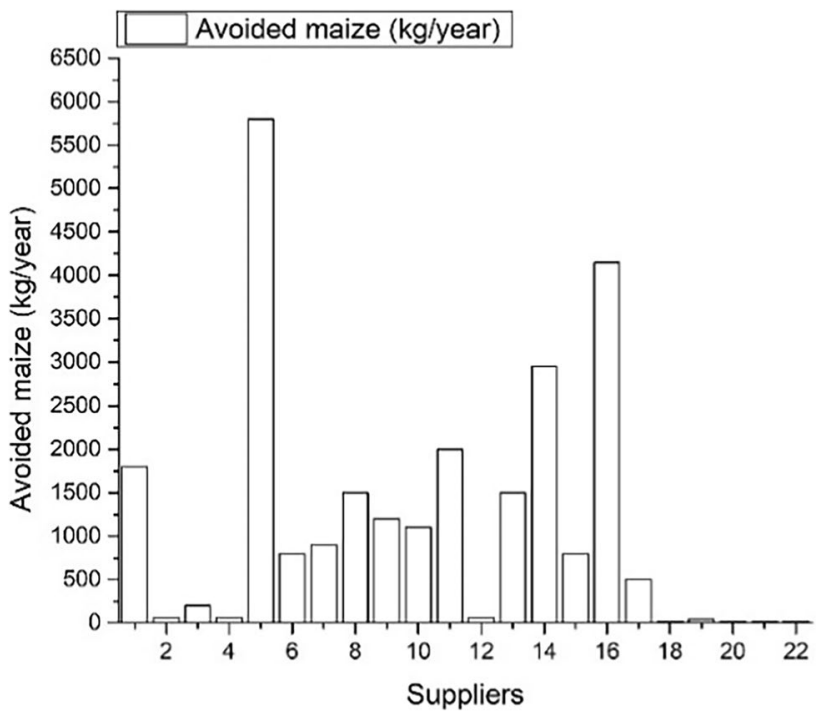

Fig. 7 Annual amount of avoided maize for each customer

\subsection{Calculation of avoided maize}

Figure 7 shows the amount of corn that can be replaced with food waste as an energy vector:

\subsection{Avoided nitrogen calculation}

Using food waste both in the energy chain (EFE) and in the reuse and reduction chain (REF) instead of using it only in the energy chains can lead also to another benefit: the avoided quantity of urea, which is the most commonly used fertilizer and which is calculated based on the amount of nitrogen contained in fertilizers. In fact, nitrogen is the 
primary and the largest nutrient that is required for plant growth but it is also involved in several types of emissions (NH3, NOx, N2O, $\mathrm{NO}^{-}$). As usual, we summed up the annual avoided nitrogen for each customer, as shown in Fig. 8.

\subsection{Results of the optimization routine}

Once all the inputs were loaded in our program and standard calculations were performed, we obtained the following output results (see Fig. 9).

This was achieved by entering a target annual collection of 2500 tons of food waste. The final results of the technoeconomic optimization are shown in Table 6.

\subsection{The graphical user interface}

Once verified that our Python tool worked properly, it was made available for everyone, by uploading it on the PythonAnywhere website. The interface was created by using FLASK, which is a framework that allows developers to easily create web applications and web servers. It is widely used, since it can work with different libraries. Done that, the program was uploaded on the web using PythonAnywhere, as it makes it easy to create and run Python programs in the cloud. Developers can write their programs in a webbased editor or just run a console session from any modern web browser. This platform provides the storage space on its servers, so that programmers can preserve their session state and access it from anywhere, with no need to pay for, or to configure, their own server.

In Fig. 10, it is shown the Homepage of the i-REXFO website where the tool is available for users. By pressing the START button, the work session begins and the user is allowed either to create an account or to login.

The results of the logistics optimization are shown in Fig. 11.

\section{Discussion}

\subsection{Development of business models for the circular economy}

Circular business models are getting more and more diffused and popular. Starting from product design, which recently has been more and more influenced by circular economy and the needs of recyclability, see [37], to the development of circular startups based on the promotion of recycle and sustainable production of goods and services, see [38].

In the study on the evolution between linear business models to circular business models [39], made by the Department of Management, Economics and Industrial
Engineering of the Polytechnic University of Milan, it is stated that among managerial practices for the transition to the circular economy, the following can be put in place: product design for circularity (among which we find Design for Recycling, Design for Remanufacturing and Reuse, Design for Disassembly, and Design for the Environment as examples); product and process optimization for resource efficiency (among which we find Resource Efficiency Measures and LCA as examples of techniques); selection of partners along the supply chain in a sustainability outlook; interventions on key activities which range from production, reverse logistics systems, R\&D\&I, and sales; energy efficiency practices and integration of renewable energy sources; exploitation of waste as a resource or a raw material; direct involvement of customers in the design phases (for example); and communication of circularity.

In the business model analyzed in this study, the critical costs are represented by:

-Cost of transport

-Cost of plant

-Cost of energy

The costs of transport have been evaluated based on the following equation:

$T C=d \times F C \times F P+d / s \times M P C$

where TC represents the cost of transport, $d$ is the distance, FC is the fuel consumption, and FP is the fuel price; $s$ is the average speed of the transport mean and MPC is the man power hourly cost.

The importance of transport costs and of the optimization of logistics is of paramount importance in the circular

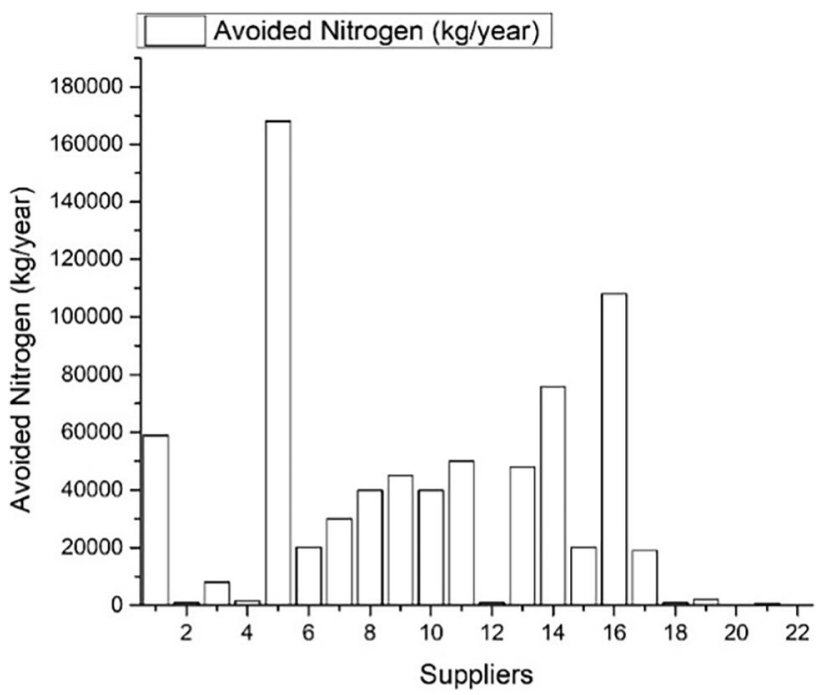

Fig. 8 Annual avoided nitrogen for each customer 
a)
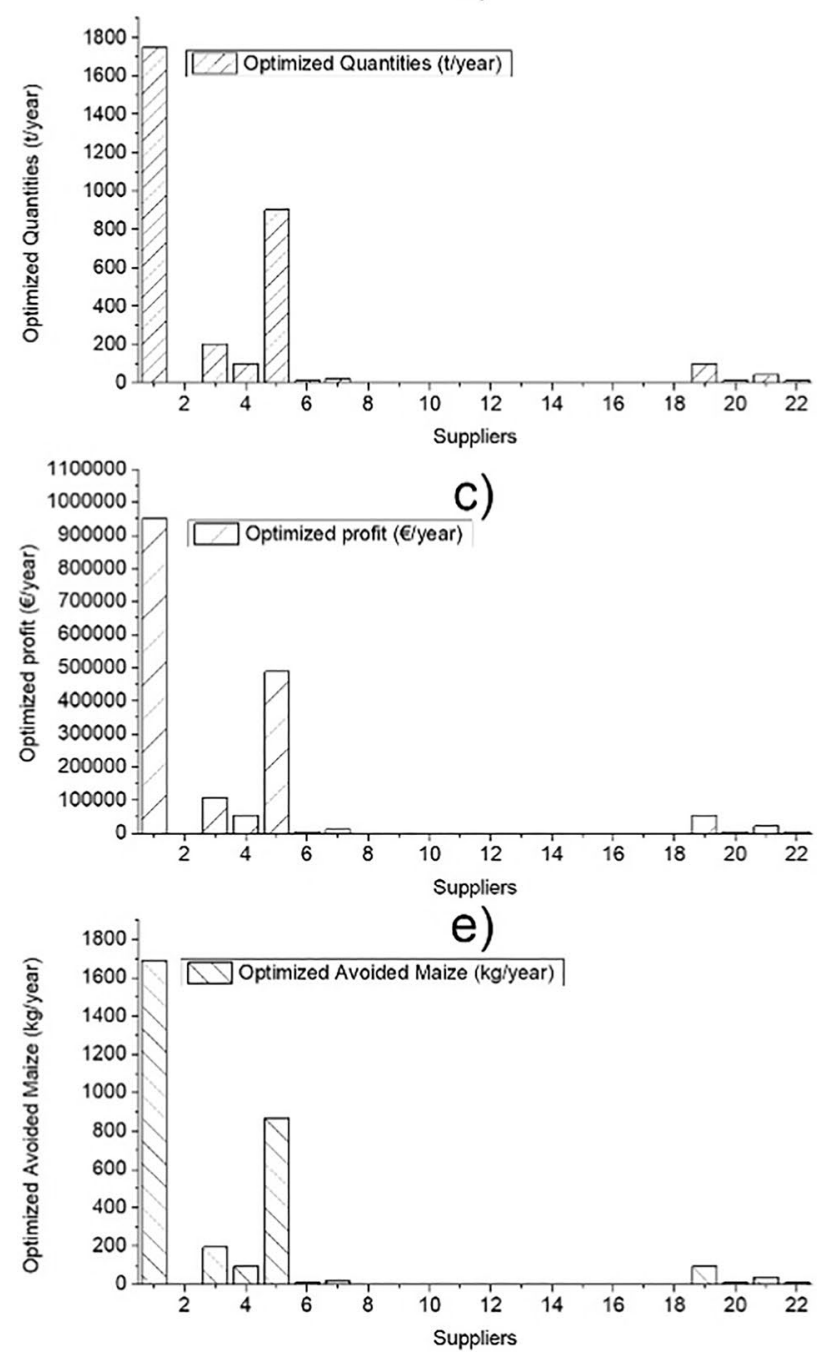

Fig. 9 a) Total optimized quantities for each customer; b) annual produced methane related to optimized quantities; c) annual profit for each customer related to the optimized quantities; d) annual electric-

Table 6 Results of the techno-economic and environmental optimization routine

\begin{tabular}{lc}
\hline Parameter & Value \\
\hline Annual food waste use in the EFE chain & 2,500 \\
Final profit (euro) & 572,453 \\
Biogas profit (euro) & 525,453 \\
Charity profit (euro) & 47,000 \\
Carbon footprint $\left(\mathrm{kgCO}_{2}\right.$ eq/year) & $4,492,938$ \\
Ecological footprint $\left(\mathrm{m}^{2} /\right.$ year) & 1,600 \\
Water footprint ( $\mathrm{m}^{3} /$ year) & $20,030,642$ \\
Avoided energy demand (MJ/year) & $38,763,608$ \\
\hline
\end{tabular}

b)
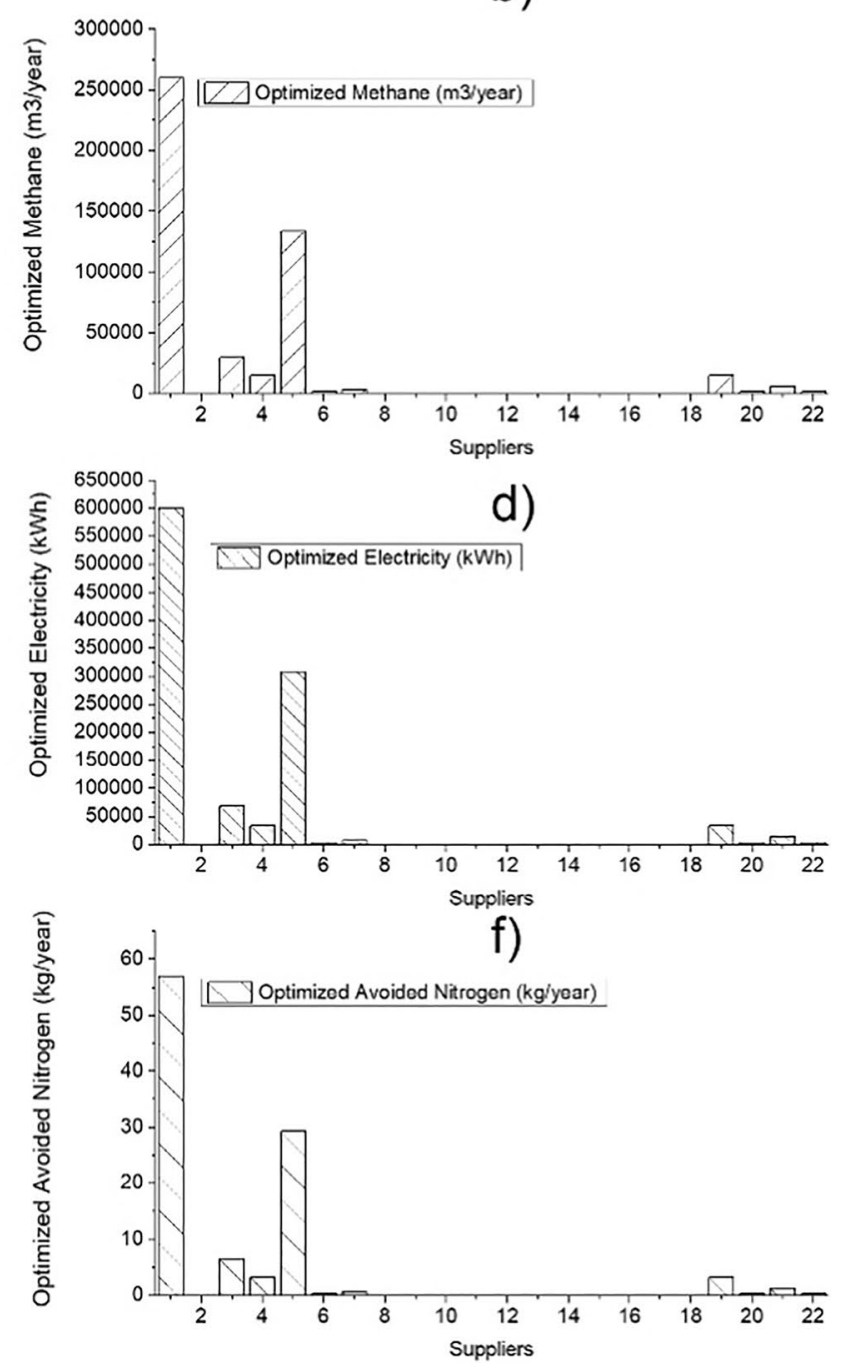

ity production related to the optimized quantities; e) annual avoided maize related to the optimized quantities; f) annual avoided nitrogen related to the optimized quantities

economy framework. In this case, an important development has been carried out by the open-source tool developed at Bath University by the research group of prof. Erdogan, see [40]. This tool has been adopted in previous publications on food waste management at the University of Perugia, see [20] and [16]. On the other hand, in the tool presented in this work, the routine for the calculation of the Vehicle Routing Problem is simplified assuming that each supplier will be reached by a truck which is responsible of reaching only one destination.

Another aspect to optimize logistics in the circular economy is the use of blockchain technology, see [41, 42]. What is proposed in most of the cases is to bring government agencies, consumers, and stakeholders on the same blockchain 


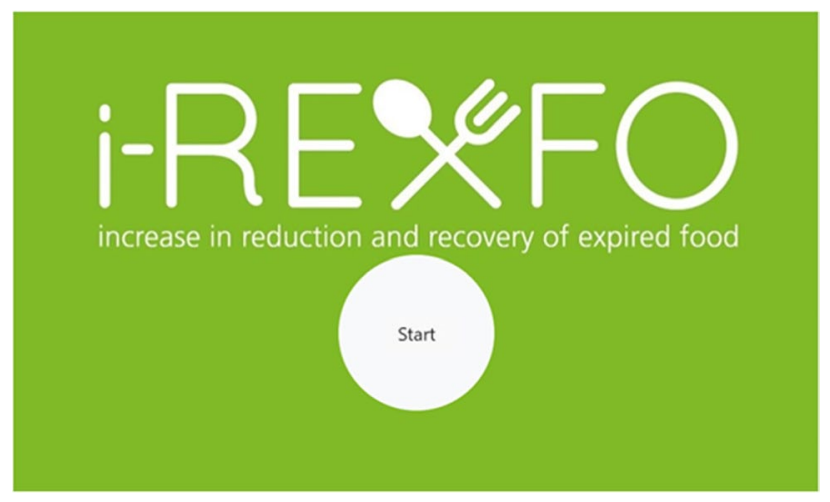

Fig. 10 Introductory page of the I-REXFO tool

platform to interrelate with smart contracts which will be used for both purposes: financial transactions and traceability. Also, the management of incentives and the regulation of the whole chain will be much easier with the support of blockchain technology. An important review on the application of blockchain technology to the food waste management supply chain is reported in [43]. Also, in this publication, it is underlined that blockchain can play an important role in business integration in the food supply chain, based on its positive characteristics of the following: transparency, traceability, and tamper resistance. Blockchain can be useful to optimize so the relationships among providers, producers, processors, distributors, retailers, and consumers. This will bring also cost reductions through automatization.
Dealing with the other types of costs which are taken into consideration in this work, the costs of investment to realize the biogas plant are dealt more in depth in Sect. 4.2. Dealing with the costs of energy, this has a double role:

1.It is for sure the cost of energy which is paid by the biogas plant due to its auto consumptions of energy;

2.It is also the spared amount of money due to the production of energy from food waste which avoids buying fossil fuels.

In both cases, we foresee the cost of energy will surely grow with the energy transition due to the switch to new technologies which are not completely competitive with the conventional fossil energy sources. In fact, according to [44] from year 2000 to year 2015, the nominal price of electricity for residential houses has almost doubled in many EU countries. This corresponds to an important decrease of energy intensity, due to the increase of energy efficiency. A similar trend to the residential sector is foreseen for the industrial sector as well.

\subsection{Importance of anaerobic digestion in the circular economy framework}

The importance of the anaerobic digestion in the framework of the circular economy is highlighted in many papers, see for example: [45-47]. Both aerobic and anaerobic treatment of organic waste and food waste assume a paramount importance in the framework of the EU directive on Waste, see [48] and [49]. While in the case of aerobic treatment, we

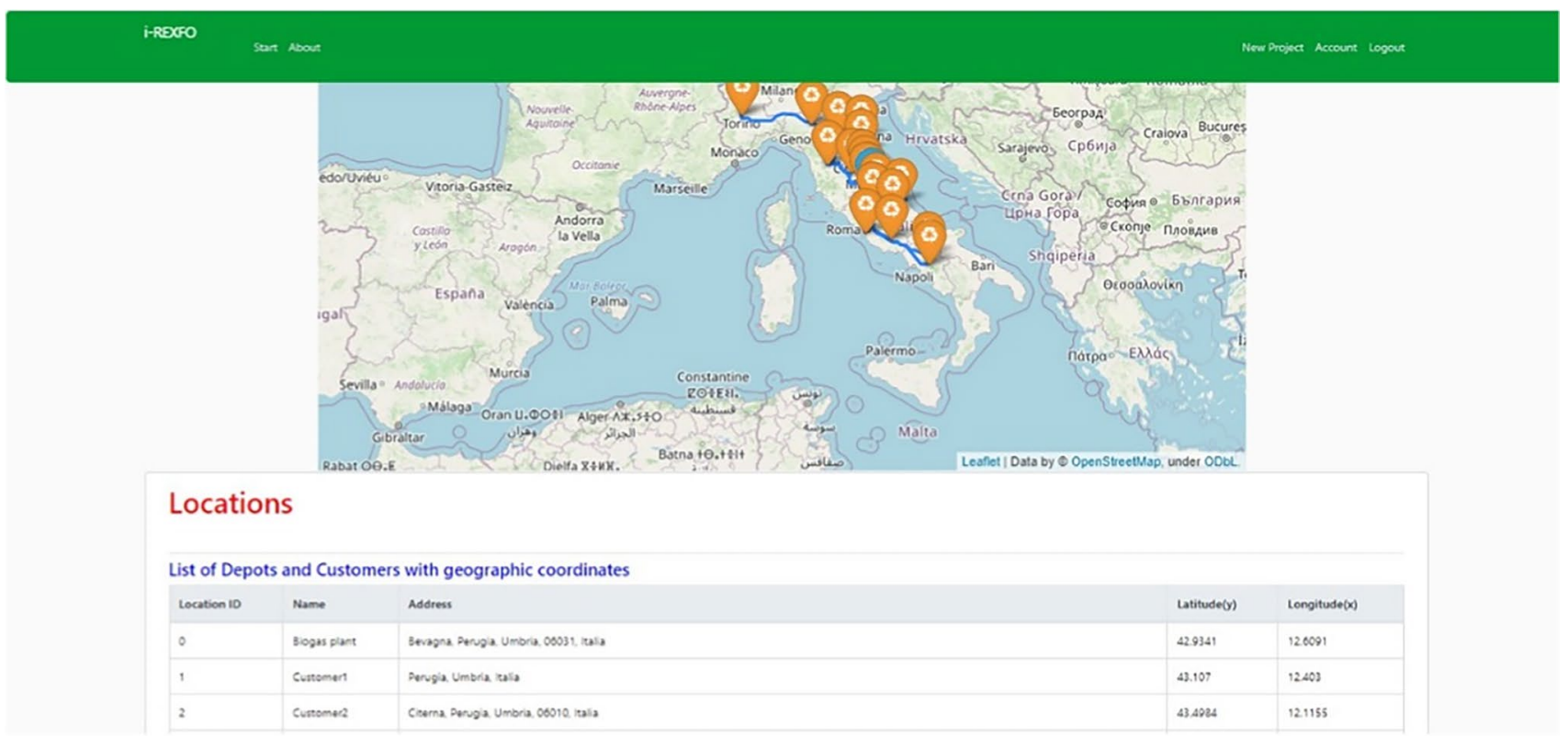

Fig. 11 Results of the logistics analysis 
have only one main product, which is compost, in the case of anaerobic digestion, we can produce up to 3 products: electricity, heat, and digestate. Both treatments are useful to avoid the disposal of the organic fractions in landfills and also to produce added value products from wastes at the end of life.

Dealing with the economic feasibility of biogas plants, this technology has undergone important learning curves which have improved its efficiency and reduced its costs. While the technology is simple and has surely reached maturity, see [50] and [51]; at the moment the main challenges and opportunities result to be:

-the optimization of the size of the plant (based also on local availability), see [52];

-the switch from energy crops to more convenient residues and waste (such as inedible food waste);

-extensive use of energy crops is a limit of the sector and influences electricity production cost;

-the cost of electricity production is still higher than that of other renewable energies (so the use of the other subproduct: heat and digestate is important for the final convenience of the supply chain);

-biomethane upgrading costs can be further decreased;

-total environmental sustainability of the chain can be increased;

-acceptance from the population and political support can be also increased for biogas plants.

\subsection{Recommendations for policy makers: the importance of LCA in the analysis of circular business models}

As it has been stated in the last paragraph, there is much to do on the sustainability of biogas production chains. In this outlook, the Life Cycle Assessment and the certification of the impacts of the electricity remain a key aspect. This can be done with Environmental Product Declarations (EPD), Product Environmental Footprints (PEF), and other single score indicators, such as carbon footprint, ecological footprint, and water footprint (as it has been done in this study).

A good approach to integrated LCA and circular economy has to be based on the development of circular economy indicators which can be modelled and calculated through LCA, for example, the circular environmental footprint formula contained in the EU Product Environmental Footprint (PEF) see for example what reported in [53]. Other important indicators which can be measured to establish if a project is conform to the circular economy practices are cite in [54]; among them, we find, for example:

- generated industrial waste (amount of waste/person);

- generated municipal waste (amount of waste/person);
- recycled industrial waste (amount of waste/person);

- recycled municipal waste (amount of waste/person);

- number of companies with zero waste programs

- LCA itself

- material productivity (regional GDP/domestic material consumption of region);

- water productivity (regional GDP/water footprint of region);

- energy productivity (regional GDP/gross inland energy consumption of region);

- GHG emissions intensity (CO2e/regional GDP);

- socio-economic indicators (employment in eco-industries; revenue in eco-industries).

\section{Conclusions}

The paper presents the development of a tool to design business models to reduce food waste generation. This has been developed within the LIFE16 project iRexfo coordinated by the University of Perugia. The tool aims at transferring the results obtained in a pilot region (Umbria, Italy) to 4 other regions in Europe. It was developed by the Department of the University of Perugia which is based on three main features:

1. A logistic optimization tool

2. A biogas yield calculator

3. An economic and environmental feasibility tool.

Based on the input data provided during the testing phase, it was inferred that the biogas plant, present in the Umbria region, can be supplied using different food waste sources which add up to the final quantity of $2500 \mathrm{t} / \mathrm{year}$. In this way, more than $3000 \mathrm{t}$ of maize can be substituted with food waste providing an improvement of the carbon footprint, environmental footprint, and ecological footprint. The environmental improvement corresponds also to a favorable economic performance of the business case developed in Umbria; in fact, thanks to the income generated by the use of $2500 \mathrm{t} /$ year of food waste for biogas production, about the same quantity of food waste can be reduced and sold to people in need due to the action of charity organizations which costs are partially covered by the production of bioenergy from food waste.

Supplementary Information The online version contains supplementary material available at https://doi.org/10.1007/s13399-021-02107-3.

Author contribution Dr. Pietro Bartocci and prof. Francesco Fantozzi conceptualized the study together with prof. Stefano Saetta and prof. Gianni Bidini. Eng. Irene Celli, Eng. Edoardo Brunori, and Eng. Michele Eugeni developed the code under the supervision of Eng. 
Cecilia Andrea Cristinuariu. Dr. Sara Massoli and Dr. Mauro Zampilli have been responsible of the laboratory analysis on biogas yields.

Funding Open Access funding provided thanks to the CRUE-CSIC agreement with Springer Nature. i-REXFO LIFE (LIFE16ENV/ IT/000547) is a project funded by the EU under the LIFE 2016 program. This work has been partially funded by the GTCLC-NEG project that has received funding from the European Union's Horizon 2020 research and innovation program under the Marie Sklodowska-Curie grant agreement No. 101018756.

Data availability Not applicable.

Code availability Not applicable.

\section{Declarations}

Ethics approval and consent to participate Not applicable.

Consent for publication Not applicable.

Competing interests The authors declare no competing interests

Open Access This article is licensed under a Creative Commons Attribution 4.0 International License, which permits use, sharing, adaptation, distribution and reproduction in any medium or format, as long as you give appropriate credit to the original author(s) and the source, provide a link to the Creative Commons licence, and indicate if changes were made. The images or other third party material in this article are included in the article's Creative Commons licence, unless indicated otherwise in a credit line to the material. If material is not included in the article's Creative Commons licence and your intended use is not permitted by statutory regulation or exceeds the permitted use, you will need to obtain permission directly from the copyright holder. To view a copy of this licence, visit http://creativecommons.org/licenses/by/4.0/.

\section{References}

1. Beretta C, Hellweg S (2019) Potential environmental benefits from food waste prevention in the food service sector. Resour Conserv Recycl 147:169-178

2. Corrado S et al (2019) Food waste accounting methodologies: challenges, opportunities, and further advancements. Glob Food Sec 20:93-100

3. United Nations Development Program UNDP (2021) Food Waste Index Report. Available online: https://www.unep.org/resources/ report/unep-food-waste-index-report-2021. Accessed 1 Dec 2021

4. Koester U, Galaktionova E (2021) FAO Food Loss Index methodology and policy implications. Stud Agric Econ 123(1):1-7

5. Food and Agriculture Organization FAO (2014) Available online: https://www.fao.org/3/i3940e/i3940e.pdf. Accessed 1 Dec 2021

6. ADEME, I.C., AK2C (2016) Food losses and waste-inventory and management at each stage in the food chain-Executive Summary

7. Laso J et al (2018) Combined application of Life Cycle Assessment and linear programming to evaluate food waste-to-food strategies: seeking for answers in the nexus approach. Waste Manag 80:186-197

8. Cristóbal J et al (2018) Techno-economic and profitability analysis of food waste biorefineries at European level. Biores Technol 259:244-252
9. Bilska B, Tomaszewska M, Kołożyn-Krajewska D (2020) Analysis of the behaviors of polish consumers in relation to food waste. Sustainability 12(1):304

10. Garcia-Herrero I et al (2018) On the estimation of potential food waste reduction to support sustainable production and consumption policies. Food Policy 80:24-38

11. Read QD, Muth MK (2021) Cost-effectiveness of four food waste interventions: is food waste reduction a "win-win?" Resour Conserv Recycl 168:105448

12. Reynolds $C$ et al (2019) Consumption-stage food waste reduction interventions-what works and how to design better interventions. Food Policy 83:7-27

13. Kwan TH, Hu Y, Lin CSK (2018) Techno-economic analysis of a food waste valorisation process for lactic acid, lactide and poly (lactic acid) production. J Clean Prod 181:72-87

14. Zhang M et al (2018) Global trends and future prospects of food waste research: a bibliometric analysis. Environ Sci Pollut Res 25(25):24600-24610

15. Beretta C, Stucki M, Hellweg S (2017) Environmental impacts and hotspots of food losses: value chain analysis of Swiss food consumption. Environ Sci Technol 51(19):11165-11173

16. Zhou $\mathrm{H}$ et al (2021) Decarbonizing university campuses through the production of biogas from food waste: An LCA analysis. Renewable Energy 176:565-578

17. Bartocci P et al (2020) Food waste anaerobic digestion in Umbria region (Italy): scenario analysis on the use of digestate through LCA. in E3S Web of Conferences

18. Alrawashdeh, K.A.B., et al (2020) Effect of heavy metals in the performance of anaerobic digestion of olive mill waste. Processes 8(9). https://doi.org/10.3390/pr8091146

19. Bartocci P et al (2020) LCA analysis of food waste co-digestion. Sci Total Environ 709. https://doi.org/10.1016/j.scitotenv.2019. 136187

20. Huiru $\mathrm{Z}$ et al (2019) Technical and economic feasibility analysis of an anaerobic digestion plant fed with canteen food waste. Energy Convers Manag 180:938-948

21. Liberti $F$ et al (2018) I-REXFO LIFE: An innovative business model to reduce food waste. in Energy Procedia

22. Young W et al (2017) Can social media be a tool for reducing consumers' food waste? A behaviour change experiment by a UK retailer. Resour Conserv Recycl 117:195-203

23. San Martin D et al (2017) Decision making supporting tool combining AHP method with GIS for implementing food waste valorisation strategies. Waste Biomass Valor 8(5):1555-1567

24. Poyatos-Racionero E et al (2018) Recent advances on intelligent packaging as tools to reduce food waste. J Clean Prod 172:3398-3409

25. Eriksson $\mathrm{M}$ et al (2019) What gets measured gets managed - or does it? Connection between food waste quantification and food waste reduction in the hospitality sector. Resour Conserv Recycl 4:100021

26. Avdiushchenko A, Zając P (2019) Circular economy indicators as a supporting tool for European regional development policies. Sustainability 11(11):3025

27. Bernad Beltrán D, Bovea edo MD and Gallardo Izquierdo A (2013) Evaluación ambiental de alternativas de gestión de residuos sólidos mediante la herramienta lca-gis-waste. Identificación de variables clave

28. van der Haar S and Zeinstra GG (2019) The impact of Too Good To Go on food waste reduction at the consumer household level: an explorative study: Wageningen Food \& Biobased Research

29. UNECE, FEEDUP. http://feedup.unece.org/about (accessed $1 / 12 / 2021)$

30. Fantozzi F, Buratti C (2009) Biogas production from different substrates in an experimental Continuously Stirred Tank Reactor anaerobic digester. Biores Technol 100(23):5783-5789 
31. Mouftahi M et al (2021) Bioenergy recovery from Southern Tunisia's organic wastes: analysis and kinetic modeling study of biomethane production. Biomass Conv Bioref. https://doi.org/10.1007/ s13399-021-01684-7

32. Mouftahi M et al (2021) Biomethanation potential (BMP) study of mesophilic anaerobic co-digestion of abundant bio-wastes in southern regions of Tunisia. Processes 9(1):1-16

33. Mouftahi M et al (2020) Bio-methanisation potential (BMP) test for organic waste available in the south region of Tunisia. in 11th International Renewable Energy Congress, IREC 2020

34. Liberti $F$ et al (2019) An incubation system to enhance biogas and methane production: A case study of an existing biogas plant in Umbria, Italy. Processes 7(12). https://doi.org/10.3390/pr7120925

35. Fantozzi $\mathrm{F}$ et al (2015) Anaerobic digestion of spoiled milk in batch reactors: technical and economic feasibility. In Energy Procedia. https://doi.org/10.1016/j.egypro.2015.12.101

36. Fantozzi F, Buratti C (2011) Anaerobic digestion of mechanically treated OFMSW: experimental data on biogas/methane production and residues characterization. Biores Technol 102(19):8885-8892

37. Sumter D, Bakker C, Balkenende R (2018) The role of product design in creating circular business models: a case study on the lease and refurbishment of baby strollers. Sustainability 10(7):2415

38. Henry M et al (2020) A typology of circular start-ups: an analysis of 128 circular business models. J Clean Prod 245:118528

39. Franzò $\mathrm{S}$ et al (2021) Unravelling the design process of business models from linear to circular: an empirical investigation. Bus Strateg Environ 30(6):2758-2772

40. Erdoğan G (2017) An open source spreadsheet solver for vehicle routing problems. Comput Oper Res 84:62-72

41. Gupta N and Bedi P (2018) E-waste management using blockchain based smart contracts. in 2018 International Conference on Advances in Computing, Communications and Informatics (ICACCI). IEEE

42. Laouar MR, Hamad ZT and Eom S (2019) Towards blockchainbased urban planning: application for waste collection management. in Proceedings of the 9th International Conference on Information Systems and Technologies

43. Li K, J-Y. Lee and Gharehgozli A (2021) Blockchain in food supply chains: a literature review and synthesis analysis of platforms, benefits and challenges. International Journal of Production Research: 1-20

44. Verbič M, Filipović S, Radovanović M (2017) Electricity prices and energy intensity in Europe. Util Policy 47:58-68

45. Wainaina $S$ et al (2020) Resource recovery and circular economy from organic solid waste using aerobic and anaerobic digestion technologies. Bioresour Technol 301:122778

46. Fagerström A et al (2018) The role of anaerobic digestion and biogas in the circular economy: IEA Bioenergy

47. Loizia P, Neofytou N, Zorpas AA (2019) The concept of circular economy strategy in food waste management for the optimization of energy production through anaerobic digestion. Environ Sci Pollut Res 26(15):14766-14773

48. Vehlow J et al (2007) European Union waste management strategy and the importance of biogenic waste. J Mater Cycles Waste Manage 9(2):130-139

49. Secondi L, Principato L, Laureti T (2015) Household food waste behaviour in EU-27 countries: A multilevel analysis. Food Policy $56: 25-40$

50. Benato A, Macor A (2019) Italian biogas plants: trend, subsidies, cost, biogas composition and engine emissions. Energies 12(6):979

51. Bremond, U., et al., A vision of European biogas sector development towards 2030: Trends and challenges. Journal of Cleaner Production, 2021. 287: p. 125065.

52. Walla C, Schneeberger W (2008) The optimal size for biogas plants. Biomass Bioenerg 32(6):551-557

53. Schrijvers DL, Loubet P, Weidema BP (2021) To what extent is the Circular Footprint Formula of the Product Environmental Footprint Guide consequential? J Clean Prod 320:128800

54. Smol M, Kulczycka J, Avdiushchenko A (2017) Circular economy indicators in relation to eco-innovation in European regions. Clean Technol Environ Policy 19(3):669-678

Publisher's note Springer Nature remains neutral with regard to jurisdictional claims in published maps and institutional affiliations. 